\title{
O comportamento de busca de informação sob o enfoque da cognição situada: um estudo empírico qualitativo
}

\author{
Ludmila Venâncio \\ Mestre em ciência da informação pela ECI-UFMG. \\ E-mail: ludmilasalomao@gmail.com \\ Mônica Erichsen Nassif \\ Doutora em ciência da informação. \\ E-mail:mnassif@eci.ufmg.br
}

\section{Resumo}

0 artigo apresenta uma pesquisa empírica qualitativa que investigou 0 comportamento de busca de informação de pessoas responsáveis pela tomada de decisão organizacional. Na primeira etapa, uma situação de tomada de decisão inesperada, equívoca e mal definida foi selecionada entre as descritas por quatro empresas de médio porte de Belo Horizonte. Na segunda etapa, foram realizadas entrevistas semi-estruturadas com os seis executivos que vivenciaram a situação escolhida. A análise dos dados empíricos obtidos mostrou como os comportamentos de busca de informação dos entrevistados, na situação específica, foram influenciados por suas histórias pessoais, pelas interações e relações estabelecidas com outros sujeitos e por suas disposições emocionais. Argumenta-se que a cognição situada possibilita uma abordagem inovadora para 0 estudo de busca de informação e pode contribuir, de forma significativa, para os estudos de usuários na ciência da informação.

\section{Palavras-chave}

Comportamento de busca de informação. Cognição situada, usuários de informação. Abordagem cognitivista, tomada de decisão.

\section{The information-seeking behavior grounded on the situated cognition approach: an empirical and qualitative study}

\begin{abstract}
This article presents an empirical and qualitative study that investigated the information-seeking behavior of persons in charge of organizational decisionmaking. In the first stage, an equivocal, unexpected and ill-defined decisionmaking situation was selected from situations described by managers of four medium-sized firms in Belo Horizonte city. In the second stage the six managers who lived the situation were interviewed in a semi-structured way. Analysis of the empirical data revealed that, in the specific situation, the information-seeking behavior of the executives was influenced by their life histories, their emotional dispositions and the relations and interrelations established with other subjects. It was argued that situated cognition is an innovative approach for the study of information-seeking behavior, which can contribute significantly to user studies in the field of information science.
\end{abstract}

\section{Keywords}

Information-seeking behavior. Situated cognition. Information users. Cognitive approach. Decision making.

\section{INTRODUÇÃO}

No campo da ciência da informação, os estudos de comportamento de busca de informação são, em sua maioria, baseados na abordagem cognitivista. Essa abordagem compreende a informação como um fator de mudança das estruturas cognitivas do indivíduo e considera o comportamento informacional constituído de fases que o indivíduo experiencia na resolução de uma situação problemática ou vazio cognitivo, cuja transposição é viabilizada pela assimilação de informação.

Embora sejam o padrão das pesquisas no campo da ciência da informação, os princípios das abordagens cognitivistas mostram-se freqüentemente inadequados para o estudo do comportamento de busca de informação do usuário, tanto por considerá-lo restritivamente como um indivíduo processador de informações, quanto enfatizar a natureza individual de suas estruturas cognitivas, colocando em segundo plano as relações sociais e os contextos de ação nos quais ele está inserido.

Em oposição a essa visão tradicional, situam-se algumas abordagens cognitivas contemporâneas, entre elas a cognição situada. Sob essa perspectiva, o usuário é um ser que vive uma série de experiências pessoais e intransferíveis, determinadas por sua estrutura biológica e história particular, mas que, ao mesmo tempo, permanece em contínua interação com outros sujeitos em diversos domínios de ação, operando emocionalmente e na linguagem.

Nos estudos organizacionais, a busca de informação é freqüentemente associada à tomada de decisão. A literatura sobre processos decisórios discute modelos que oscilam em um continuum que vai desde modelos mais formais e processuais - adequados para situações em que os problemas são bem definidos e os objetivos e técnicas são claros para os membros da organização, até modelos menos formais, que privilegiam aspectos como emoção, experiências vivenciadas e relações pessoais para a análise de situações inesperadas, incompreensíveis, pouco definidas e com alto nível de equivocidade e incerteza percebidas.

Nesse contexto, este artigo apresenta os resultados de uma pesquisa empírica qualitativa, que analisou o comportamento 
de busca de informação de pessoas responsáveis pela tomada de decisão organizacional, com base nos princípios da cognição situada. Procurou-se responder à seguinte questão: Como as disposições emocionais dos sujeitos, suas histórias pessoais e suas histórias de relações com o meio influenciam o que se determina como informação e a conduta para ter acesso a essa informação, em uma situação de tomada de decisão?

Dada a subjetividade, a fluidez e o caráter exploratório do tema estudado, uma abordagem qualitativa foi considerada a mais indicada para o desenvolvimento do estudo empírico. Assim, a preocupação metodológica centrou-se na utilização de métodos e técnicas que fossem coerentes com as bases teóricas adotadas. A pesquisa foi realizada em duas fases distintas, o que possibilitou adequada seleção da situação de tomada de decisão a ser estudada (na primeira fase) e maior aproximação com os entrevistados para identificação de suas condutas informacionais no domínio de suas empresas (na segunda fase). Foram realizadas entrevistas semi-estruturadas pessoais com empresários de organizações de médio porte e uma análise temática de conteúdo dos dados obtidos. Nas entrevistas, procurou-se distinguir as influências das disposições emocionais dos decisores, das histórias particulares e das histórias de relação com outros sujeitos em suas condutas de busca de informação, assim como compreender como eles estabelecem redes de interações e relações com outros sujeitos e de que modo essas redes influenciam a busca de informação.

A pesquisa apresentada neste artigo buscou analisar situações de tomada de decisão consideradas altamente ambíguas, equívocas, incertas, freqüentes no cotidiano organizacional, especialmente em fases de mudanças, e que repercutem intensamente no desempenho da organização, situações essas adequadas para a análise com base no corpo teórico empregado.

Dessa forma, este estudo compreendeu o comportamento de busca de informação como a conduta interativa e social para ter acesso à informação, abrangendo a escolha e uso das fontes e, também, as percepções referentes à acessibilidade e à confiabilidade das fontes, as quais influenciam a busca de informação.

Este artigo estrutura-se em seis seções. Na seção que se segue apresentam-se os fundamentos relativos aos fenômenos cognitivos como propugnados na cognição situada e os conceitos de informação e conhecimento no âmbito dessa abordagem. Em seguida, na terceira seção, discutem-se modelos tradicionais de comportamento de busca de informação, procurando destacar os aspectos convergentes e divergentes em relação à perspectiva cognitiva adotada pelo estudo. $\mathrm{Na}$ quarta seção, relatam-se os procedimentos metodológicos. Os dados da pesquisa, bem como a análise dos mesmos, são apresentados na quinta seção. E por fim, na sexta seção, são sintetizadas algumas considerações sobre o estudo.

\section{COGNIÇÃO SITUADA: PRINCÍPIOS PARA A COMPREENSÃO DA DINÂMICA SOCIAL HUMANA, DA INFORMAÇÃO E DO CONHECIMENTO}

Especialmente nas três últimas décadas, reflexões teóricas e epistemológicas têm ensejado uma redefinição das relações existentes entre a biologia humana, a cognição, a linguagem e a emoção. Essa reorientação nas linhas de pensamento, em diversos campos de estudos, evidencia a necessidade de considerar os seres humanos como seres históricos, sociais e contingentes, de atentar para suas histórias particulares e de interação com outros sujeitos, e de reconhecer a importância do domínio lingüístico como especificador dos processos cognitivos.

São essas orientações teóricas que norteiam as abordagens mais recentes das ciências cognitivas, mais especificamente, o arcabouço teórico conceitual que, na literatura, tem sido denominado cognição situada. A cognição situada refere-se a um conjunto de teorias que abordam a cognição sob um ponto de vista contemporâneo e integrado, dentre as quais: Biologia do Conhecer, proposta por Maturana (1997, 1998, 2001); Enaction, desenvolvida por Varela, Thompson e Rosch (1991); Situated Cognition, apresentada por Clancey (1997), e Ecologia da Mente, proposta por Bateson (1972).

O ponto fundamental que une essas abordagens é a utilização do mesmo princípio epistemológico na constituição de suas teorias. Tal princípio considera a existência do organismo-emseu-ambiente, ou seja, organismo e ambiente constituem uma unidade inseparável, sendo o processo de interação entre eles contínuo e simultâneo.

Em oposição à abordagem cognitivista, vertente dominante das ciências cognitivas, que pressupõe a existência de um mundo anterior à experiência do indivíduo cujas características e relações podem ser captadas e representadas em sua mente (representações simbólicas de características ambientais extrínsecas), Maturana e Varela (2004) consideram os sujeitos como "sistemas fechados operacionalmente e determinados estruturalmente". Por sistemas determinados estruturalmente entendem-se os sistemas em que nada que lhes seja externo possa especificar as mudanças estruturais pelas quais eles passam em conseqüência de uma interação (ou seja, não admitem interações instrutivas). Um agente externo que interage com um sistema estruturalmente determinado pode somente desencadear mudanças estruturais determinadas pelo próprio sistema. Desse modo, esses sistemas fechados não operam por representações, uma vez que são definidos por mecanismos internos de auto-organização.

Como resultado desse determinismo estrutural, um organismo vive em constante interação no meio, de maneira codeterminada. Enquanto houver essa congruência, meio e organismo atuarão como possíveis perturbações mútuas que 
desencadearão (ou não) mudanças estruturais. Ao especificar quais perturbações vindas do meio desencadeiam suas mudanças, o ser vivo "cria um mundo", como expresso por Maturana e Varela (2004). Desse modo, a cognição não é a representação do mundo que existe de maneira independente, mas, ao contrário, é uma contínua atividade de criar um mundo por meio do processo de viver.

Na cognição situada, também é ressaltado o papel fundamental da linguagem como mecanismo de interação entre os sujeitos e a participação da emoção na determinação dos diversos domínios no qual se atua. A linguagem não é vista como um sistema de signos e regras que medeiam os esquemas conceituais do indivíduo e o mundo em que ele vive. Linguagem é comportamento, é atividade que se realiza nos encontros históricos, contingentes, consensuais, recorrentes e recursivos entre sujeitos em interação (MATURANA, 1997, 1998). Emoção e linguagem se entrelaçam na medida em que o fluir na linguagem modifica o emocionar e as emoções dispõem os sujeitos a distintos modos de colocação na linguagem. As emoções são disposições corporais dinâmicas que especificam o domínio de ação em que os sujeitos se movem a cada instante. Quando os sujeitos se dispõem dos diversos modos possíveis, certas ações são viabilizadas, enquanto outras, não. Assim, quando os sujeitos se movem sob determinada emoção, aceitamse certas premissas que não seriam aceitas em outras condições; ou, inversamente, já não se aceitam determinadas premissas que poderiam ser aceitas, guiados por novas emoções.

Considerando os conceitos relativos ao interacionismo, à linguagem e à emoção, a informação e o conhecimento podem ser analisados sob um novo enfoque, a partir da cognição situada. Em oposição às concepções da informação como algo captado de uma realidade objetiva e externa, capaz de modificar as estruturas cognitivas do indivíduo, como nos moldes da abordagem cognitivista, a cognição situada permite compreender a informação como uma construção realizada pelos sujeitos, a partir das realidades sócio-históricas vivenciadas por eles. Em decorrência da organização operacionalmente fechada dos seres vivos e de sua dinâmica estrutural necessariamente congruente com o meio, a informação é vista como uma perturbação da estrutura biológica do sujeito, a qual pode, ou não, ser determinada em função da sua própria estrutura e da história de suas interações com o meio. Dessa forma, as informações não são captadas do meio, ao contrário, constrói-se um mundo ao especificar quais as configurações do meio são perturbações e que mudanças estas desencadeiam em um organismo.

O conhecimento não se limita ao processamento de informações oriundas de um mundo anterior à experiência do observador, não é passivo, mas, sim, construído pelo ser vivo em suas interações com o mundo. Conhecer não é um processo de captação e acumulação de características de um ambiente externo constituindo representações internas que serão posteriormente rememoradas e computadas, mas está relacionado às mudanças estruturais que ocorrem no organismo de maneira contingente com sua história de interações com o meio.

\section{ANÁLISE DO ESTUDO TRADICIONAL DO COMPORTAMENTO DE BUSCA DE INFORMAÇÃO}

Tendo em vista as semelhanças com a perspectiva cognitiva adotada no estudo realizado, foram analisados a abordagem do sense-making de Dervin $(1983,1992)$ e o modelo processual de busca de informação de Kuhlthau (1991, 1993a). Embora essas teorias ainda possuam em suas propostas conceitos relacionados às abordagens cognitivistas, alguns de seus esforços para compreensão da busca de informação merecem ser destacados. Essa análise possibilita, ainda, apontar limitações e discriminar perspectivas que são evidenciadas pela cognição situada.

\section{A abordagem do sense-making: situação, gap e uso na busca de informação}

A abordagem cognitiva do sense-making desenvolvida por Brenda Dervin consiste em um conjunto de premissas conceituais e métodos de avaliação que procuram compreender como as pessoas constroem sentido (sense-making) em suas realidades e como elas utilizam informações nesse processo (DERVIN, 1983). O fenômeno do sense-making, foco de estudo da abordagem, é compreendido como a atividade humana de observação e interpretação do mundo exterior, na qual são construídos sentidos pela utilização de esquemas mentais prévios em um contexto sociocultural.

Nos estudos de busca e uso da informação, a metodologia do sense-making é associada ao deslocamento da ênfase colocada nos sistemas de informação (correspondência entre uma busca de informação e a recuperação de documentos) para os usuários de informação (correspondência entre o sistema e a necessidade de informação). Esse direcionamento do enfoque para os usuários individuais é percebido em Dervin pela análise dos processos de busca e uso da informação como práticas comunicacionais produzidas e reproduzidas por diferentes indivíduos, nos diversos contextos em que atuam.

Um pressuposto básico da teoria reside na idéia de descontinuidade. Segundo Dervin (1992), a descontinuidade é um aspecto central da realidade, presente em todas as situações vivenciadas pelo ser humano. O indivíduo cria sentido para transpor os gaps cognitivos que lhes são apresentados em decorrência da descontinuidade sempre presente na realidade, incompleta e inconstante.

O estado cognitivo do indivíduo é representado metaforicamente como um movimento contínuo, no tempo e no espaço, no qual o próprio indivíduo cria sentido para suas ações e para 
o ambiente. Contudo, a todo momento, ele se depara com situações problemáticas (barreiras, confusões, dilemas e desordens) que o impedem de prosseguir devido à percepção de um vazio cognitivo. Ele, então, tenta compreender tal vazio, e, baseado na interpretação resultante, determina as estratégias para superá-lo.

Assim, a teoria enfatiza: (a) as situações experienciadas pelos indivíduos em um contexto temporal e espacial no qual surgem as necessidades de informação, influenciadas pela experiência e pelas histórias de vida do indivíduo; (b) os gaps cognitivos enfrentados (necessidades de informação, questões que as pessoas têm quando constroem sentido e movem-se através do tempo-espaço) que são representados pelas angústias, desordens e confusões; (c) o uso da informação, ou seja, as pontes ou estratégias construídas (idéias, pensamentos, atitudes) para superação dos gaps.

A abordagem do sense-making, como demonstrado até o momento, tem enfatizado o indivíduo e o mundo interno desse indivíduo (sense-making visto como um esquema pessoal de referências), não atentando para as dimensões coletivas do processo de construção de sentido. Entretanto, a partir do início da década de 90, Dervin tenta superar essa visão individualista, direcionando sua atenção para fatores mais sociais, como o contexto e o sense-making coletivo. Como exemplo dessa tendência, a metodologia passou a destacar a verbalização (verbing) - utilização, pelo entrevistado, de verbos em vez de substantivos - para a caracterização da situação vivenciada pelo indivíduo no processo de construção de sentido. Ao superar a antiga ênfase dada ao substantivo, Dervin (1993) realça a importância da ação descrita pelo verbo, agora construída na linguagem (construção coletiva e social). A ênfase passa a estar nas ações e movimentos realizados pelos indivíduos, que revelam na linguagem as motivações cognitivas e emocionais durante o processo de busca de informação e procuram solucionar o problema vivido (gap).

\section{O processo de busca de informação de Kuhlthau: dimensões físicas, cognitivas e afetivas}

O processo de busca da informação é visto por Kuhlthau (1991, 1993a) como uma atividade realizada pelo indivíduo para dar sentido a uma informação e para ampliar seu estado de conhecimento sobre um problema ou tópico específico. A incerteza diante da falta de compreensão, de um vazio de significado, de uma construção limitada com relação a algum assunto ou situação problemática, dá início ao processo. A informação é vista como um elemento que auxilia a transposição do gap cognitivo existente entre o conhecimento sobre o problema e o que o indivíduo necessita saber para solucioná-lo.

De certa forma, Kuhlthau (1991, 1993a) incorpora alguns conceitos da abordagem cognitivista, ao evidenciar que o processo de interação entre o indivíduo e uma determinada estrutura de informação gera uma modificação no seu estado cognitivo, produzindo conhecimento que se relaciona corretamente com a informação recebida. No entanto, a autora supera a dimensão estritamente cognitivista ao valorizar os aspectos afetivos no processo de busca, como será destacado a seguir.

O processo de busca de informação é descrito por Kuhlthau (1991, 1993a) em termos de fases, ou estágios, que representam a tarefa principal de cada ponto do processo: iniciação, seleção, exploração, formulação, coleta e apresentação. A proposição fundamental do modelo é que o indivíduo inicia a busca de informação em um estado de incerteza, ansiedade e desconfiança. À medida que o processo se desenvolve e a informação é encontrada e assimilada, as reações afetivas mudam: caso a busca seja bem-sucedida, sentimentos de confiança e satisfação aumentam; caso contrário, sentimentos de dúvida, confusão e frustração emergem. As ações do processo de busca de informação podem englobar atividades como as seguintes: reconhecer a necessidade de informação; identificar um tema geral; investigar as informações sobre o tema geral; formular o foco; reunir as informações pertinentes ao foco; completar a busca de informação.

Apesar de sugerir certa linearidade pela forma como é descrito no modelo, o processo é recursivo e interativo e raramente se desenvolve diretamente da fase de seleção para a apresentação. Tome-se, como exemplo, o estágio da formulação do foco, o qual representa o ponto crítico do processo de busca da informação e serve como orientador e selecionador de inúmeras opções, especialmente em condições de muita incerteza, ambigüidade e sobrecarga informacional. Essa etapa, após sua finalização, quando o foco é bem estabelecido, tende a propiciar certa estabilidade emocional, uma vez que a incerteza e a confusão decrescem, a confiança aumenta e o interesse se intensifica. Não obstante, é justamente nessa fase que usualmente se identificam sentimentos de ansiedade, insegurança e confusão, típicos do início da busca, quando se seleciona e explora grande quantidade de informações.

O modelo incorpora também três dimensões da experiência humana, as quais assumem características em cada estágio experienciado: a dimensão física, representada pelas ações a cognitiva, descrita pelos pensamentos, e a afetiva, por sentimentos. Nessa perspectiva, uma pessoa se move de um estado inicial de necessidade de informação para um estado final de resolução do problema, através de uma série de escolhas feitas pela conjugação de sentimentos, pensamentos e ações. A primeira dimensão, a física, coerentemente com os estudos tradicionais de busca da informação, ressalta a relação escolha-ação, na qual o indivíduo faz opções a partir de uma série de alternativas consideradas mais adequadas e oportunas em virtude do contexto e, então, age com base nas suas visões de mundo. Na segunda e terceira dimensões, caracterizadas pelos aspectos cognitivos e afetivos, evidencia-se a oscilação entre sentimentos de incerteza e de 
confiança que ocorrem durante todo o processo de busca e que moldam a maneira como o processo é experienciado. Por meio dessas dimensões, a autora apresenta as cognições e sentimentos associados aos vários estágios e atividades realizadas em um processo de busca de informação.

Ao considerar a incerteza como moduladora do processo, a autora desvincula-se da concepção tradicional da busca de informação, retratada como um procedimento sistemático e ordenado, e enfatiza a ansiedade e a confusão sentidas pelo usuário nas situações que ele experiencia (KUHLTHAU, 1993b). Ainda, grande parte dos estágios propostos pelo modelo de Kuhlthau (1991, 1993a) concentra-se nas atividades de exploração da informação e no estabelecimento do foco, contrapondo-se aos estudos tradicionais de busca de informação, que apresentam como atividades dominantes a obtenção da informação e a finalização da busca.

Há críticas a esses modelos nas quais se argumenta que a maioria dos estudos de busca de informação que adota o ponto de vista do usuário ainda permanece no nível do indivíduo e busca descrever e explicar as ações no contexto de suas experiências e interpretações subjetivas sem considerar que tais experiências e interpretações subjetivas, são um produto socialmente construído na linguagem. Como destacado por Talja, Keso e Pietiläinen (1999), as necessidades, a busca e o uso da informação não são estudados como um fenômeno sociocultural, uma vez que os fatores sociais, culturais e históricos ainda são tratados como externos ao processo de busca de informação. Em uma perspectiva mais integrativa, como proposta por Savolainen, Tuominem e Talja (2005), sob o ponto de vista do construcionismo social e em congruência com os princípios da cognição situada, o processo de busca de informação é constituído social e dialogicamente, uma vez que todas as práticas informacionais são sociais e originam-se das interações entre os diversos membros de uma comunidade. Assim, a perspectiva integrativa vê a busca de informação como um processo dinâmico, que se constitui das ações e das necessidades dos sujeitos, assim como das características físicas e sociais do ambiente no qual o sujeito reúne e utiliza a informação.

\section{PROCEDIMENTOS METODOLÓGICOS}

A pesquisa apresentada é um estudo de caso, pois se concentra em uma só organização, procurando produzir uma descrição ampla dentro do escopo estabelecido. Tendo em vista a abordagem cognitiva adotada e os objetivos propostos pela pesquisa, foram selecionadas como instrumento de coleta de dados entrevistas semi-estruturadas utilizando a técnica do incidente crítico, desenvolvida por Flanagan (1954) no Instituto Americano de Pesquisa em 1947. A técnica consiste em um conjunto de procedimentos para obter fatos importantes relacionados com o comportamento humano em situações definidas. Para que um incidente seja considerado crítico, ele deve ocorrer
... em uma situação onde o propósito ou intenção do ato pareça claro ao observador e onde suas conseqüências sejam suficientemente definidas para deixar poucas dúvidas no que se refere aos seus efeitos (FLANAGAN, 1954, p. 327).

Assim, os incidentes críticos incluem três características: (1) a descrição de uma situação recente vivenciada pelo entrevistado; (2) as ações ou comportamentos das pessoas envolvidas no incidente; (3) os resultados ou conseqüências advindos do incidente.

Para o desenvolvimento dos instrumentos de coleta de dados, dois critérios de consistência foram considerados relevantes: a confiabilidade e a validade. Com o intuito de assegurar esses critérios, os roteiros de entrevistas foram cotejados com outros instrumentos de coleta de dados aplicados em estudos que utilizam a mesma abordagem cognitiva adotada na pesquisa, como em Borges (2002). Além disso, foram realizados pré-testes com empresários de empresas de médio porte da cidade de Belo Horizonte, antes das entrevistas de cada fase da pesquisa. Nos pré-testes, buscou-se determinar se as perguntas eram perfeitamente compreendidas, se as questões eram interpretadas similarmente por todos os empresários e se as respostas eram coerentes com os objetivos de cada questão.

Na primeira fase da pesquisa, são analisadas situações de tomada de decisão. Já na segunda fase, as unidades de análise são pessoas-chave participantes de processos de tomada de decisão em uma empresa de médio porte instalada na cidade de Belo Horizonte. As empresas foram selecionadas a partir de uma listagem fornecida pela Federação das Indústrias do Estado de Minas Gerais (FIEMG). Para a escolha dessas empresas, dois critérios foram levados em consideração: primeiro, que a empresa estivesse há mais de 10 anos no mercado ${ }^{1}$; segundo, que ela atuasse nos setores mais representativos da amostra obtida. Assim, as empresas com mais de 10 anos foram divididas de acordo com suas atividades econômicas, conforme especificação da Classificação Nacional de Atividades Econômicas (CNAE), procurando-se obter certa diversificação de atividades.

Desse conjunto, foram selecionadas duas empresas do setor industrial e duas empresas do setor de serviços. No setor industrial, a primeira empresa atua na área de fabricação de medicamentos e a segunda, na tecelagem de algodão. Do setor de serviços, a primeira empresa selecionada atua na área de organização e realização de festas e eventos e a segunda exerce atividades de assistência técnica e extensão rural.

A coleta de dados foi realizada em duas fases. Na primeira fase, foram entrevistados diretores, presidentes e sócios-

1 Esse critério foi adotado com base no estudo realizado por Chér (1990), que considera as empresas de médio porte estáveis quando atuam há mais de 10 anos no mercado. 
proprietários das organizações anteriormente selecionadas. Nessas entrevistas, utilizou-se a técnica do incidente crítico para a identificação de uma situação recente, na qual foi necessário tomar uma decisão importante para a organização. Inicialmente, foram solicitadas ao entrevistado a descrição da situação e a explicitação da importância da mesma para as atividades da organização. As perguntas subseqüentes objetivaram a especificação dos propósitos e dos efeitos das ações e a categorização da situação conforme era percebida: como uma oportunidade, um problema ou uma ameaça. As demais questões referiam-se à identificação de experiências já vivenciadas pela empresa e que se relacionavam à situação descrita e à identificação das pessoas envolvidas no processo de decisão, fossem elas internas ou externas à organização.

Nessa fase, foram obtidas quatro situações descritas pelos entrevistados. Após a análise das entrevistas, a situação de tomada de decisão para o estudo de caso foi selecionada segundo cinco critérios básicos: (1) que o entrevistado tivesse participado diretamente da decisão descrita; (2) que ele conseguisse identificar todas as pessoas envolvidas na decisão tomada; (3) que os efeitos esperados da decisão fossem considerados claros pelo entrevistado; (4) que a situação descrita fosse ambígua e pouco estruturada; (5) que a descrição da situação sugerisse um envolvimento emocional do entrevistado.

Assim, identificou-se uma situação de tomada de decisão informacionalmente carregada, repleta de questões inesperadas, ambíguas, pouco definidas, com alto nível de complexidade, equivocidade e incerteza percebidas. Em oposição a situações mais bem definidas (quando os objetivos, os métodos e as técnicas são suficientemente claros para os membros da organização), em que a análise atenta para aspectos mais racionais, lineares e processuais, a análise de uma situação como a descrita deve privilegiar os aspectos contingenciais, como a emoção e as experiências vivenciadas pelos participantes.

Na segunda fase, foram entrevistadas seis dirigentes da organização escolhida envolvidos diretamente na situação de tomada de decisão. As entrevistas foram realizadas separadamente, o que possibilitou observar as tensões latentes nos discursos e como elas foram expressas de diferentes formas conforme o entrevistado. $O$ roteiro dessas entrevistas foi estruturado em dois blocos de questões. O primeiro continha perguntas sobre o entrevistado, sua história profissional, sua história de vida e sua história de relações com outras pessoas. No segundo bloco, retomou-se a situação vivenciada pelos membros da organização identificada na primeira fase de coleta de dados e analisou-se o comportamento de busca de informação de cada participante sob o enfoque cognitivo. Para tanto, foram discernidos o impacto da situação para cada entrevistado, as emoções vivenciadas durante todo o processo, as informações que ele buscou para a tomada de decisão, o motivo pelo qual optou por determinada informação em detrimento de outra, a importância dessas informações e as pessoas que influenciaram a tomada de decisão.

As entrevistas foram gravadas, transcritas e, posteriormente, analisadas com ajuda do software QSR N6 ${ }^{2}$, que possibilita um tratamento dos dados qualitativos. Para a interpretação dos dados, efetuou-se uma análise temática de conteúdo com o objetivo de descobrir os diversos núcleos de sentido (temas) relacionados ao comportamento de busca de informação identificados nos discursos dos sujeitos entrevistados (STRAUSS, 1987; BARDIN, 1988). A análise, realizada em três etapas, de maneira recursiva, envolveu: (1) a préanálise das entrevistas, que englobou a organização e sistematização dos dados obtidos, e a criação de categorias de análise agrupando elementos, idéias e expressões em torno dos conceitos discutidos pelo referencial teórico, com foco nos seguintes temas: emoções vivenciadas na busca de informação, história de vida dos entrevistados, história de interações dos entrevistados, situação de tomada de decisão e busca de informação (fontes de informações utilizadas e tipos de buscas); (2) a exploração e a codificação dos dados da entrevista; (3) a interpretação dos resultados com base nos pressupostos estabelecidos.

\section{APRESENTAÇÃO E DISCUSSÃO DOS RESULTADOS}

Na primeira fase de entrevistas, foram identificadas quatro situações de tomada de decisão. Três delas foram percebidas pelos entrevistados como problemas ou ameaças: (1) a decisão de paralisação das atividades de produção da indústria de tecelagem devido ao aumento considerável do estoque; (2) a decisão de rompimento de contrato com o shopping onde a empresa que atua na área de organização e realização de eventos possuía um salão de festas, devido à instalação de uma faculdade no mesmo estabelecimento; (3) a decisão de ampliação de uma nova área da indústria farmacêutica tendo em vista demandas do mercado. A situação percebida como oportunidade referiase à criação de uma infra-estrutura para a rede tecnológica, descrita pela empresa que atua na área de assistência técnica e extensão rural, visando à integração interna da empresa, dada a disponibilidade financeira naquele momento.

A escolha da situação baseou-se nos cinco critérios anteriormente relacionados nos procedimentos metodológicos. A situação escolhida foi descrita pela empresa atuante no mercado de festas e eventos. A entrevistada, dada a posição que ocupa na empresa (diretora comercial), juntamente com outros funcionários por ela identificados, teve uma participação intensa e ativa na situação descrita. Quando relatou a decisão, a entrevistada

2 Nome dado à nova versão do software NUD*IST (Non-numerical, Unstructured Data Indexing, Searching, and Theorizing) 
expressou clareza quanto às suas intenções, apesar de descrever uma situação não usual e caracterizada por muitos componentes. Por fim, durante todo o seu relato, a entrevistada demonstrou grande envolvimento emocional com a situação narrada.

\section{Análise do comportamento de busca de informação sob o enfoque da cognição situada}

Escolhida a situação para o estudo, na segunda fase da pesquisa, procurou-se analisar o comportamento de busca de informação dos entrevistados à luz dos princípios da cognição situada. Desse modo, admitiu-se que o comportamento de busca de informação dos sujeitos, em suas múltiplas interações e relações, é influenciado: (a) pela história pessoal dos sujeitos e pelas experiências vivenciadas por eles; (b) pelas disposições emocionais individuais especificadoras dos domínios de ação em que os sujeitos se movem; (c) pela história profissional na organização e em outras empresas; (d) pela história de interações e relações estabelecida com outros membros da organização e com pessoas externas à empresa.

Durante a análise, esses pressupostos foram relacionados com os resultados obtidos nas entrevistas enfatizando-se os aspectos de busca de informação. Para tanto, considera-se que a situação específica descrita e vivenciada pelos entrevistados pode ser mais bem exposta e analisada a partir de sua divisão em quatro fases, a saber: (1) a compreensão inicial da situação - que envolve as primeiras percepções dos entrevistados em relação ao problema apresentado; (2) a configuração da situação - que abrange os esforços para compreender o ocorrido e para determinar a amplitude de suas conseqüências; (3) a definição de cursos de ação a serem seguidos - na qual se analisam as buscas de informação para reformulação da situação e para determinação de possíveis soluções; (4) a reconfiguração da situação - em que se apresenta a compreensão atual da situação, contrastada com a inicial e as diferentes maneiras como as pessoas compreendem e experienciam a situação.

Ao final desta seção, é exibido um quadro onde são sintetizados os resultados da pesquisa. São apontadas as principais características das fases analisadas, o uso da informação, as principais fontes de informações utilizadas, as percepções das fontes de informações, as emoções envolvidas e a importância da história de relações e interações em cada fase. A seguir, serão descritas cada uma das fases sumarizadas nesse quadro, destacando seus principais aspectos.

Os entrevistados descreveram a situação de rompimento de contrato com um shopping, onde o buffet possuía um salão de festas, devido à entrada de uma faculdade nos demais andares do mesmo estabelecimento. A situação surgiu de uma forma totalmente inesperada, uma vez que a empresa havia renovado o contrato de locação (e o fazia há 12 anos), quando foi veiculada uma notícia no jornal e uma propaganda em um outdoor sobre a entrada da faculdade no local. Considerando inverídica a informação, a empresa procurou a diretoria do shopping, que desmentiu a notícia. Depois de alguns meses, ela foi surpreendida com o cancelamento de um casamento devido à possível instalação da faculdade. Novamente a empresa procurou a diretoria do shopping, que continuou negando a situação. Passados cinco meses desde a veiculação da notícia, a empresa teve, finalmente, a confirmação de sua veracidade. $\mathrm{O}$ problema surgiu devido à incompatibilidade das atividades operacionais da faculdade e do salão de festas. Este sempre teve uma grande aceitação, em virtude da comodidade e da segurança proporcionadas pela sua localização e o amplo estacionamento. Com a entrada da faculdade, a área do estacionamento ficou dividida entre os clientes e os estudantes, e o barulho proveniente dos corredores comprometia as festas realizadas durante a semana. Inúmeros contratos foram cancelados, acarretando grandes prejuízos. Diante da situação, o buffet, inicialmente, resolveu não assumir novos compromissos que utilizassem o espaço, cumprir todos os contratos de festas e eventos e, então, sair do shopping.

De maneira geral, a partir dos dados obtidos nas entrevistas, foi possível observar que um aspecto importante do comportamento informacional dos entrevistados refere-se à preocupação constante em acompanhar o ambiente de negócios da empresa. Em razão desse comportamento e tendo renovado o contrato de locação com o shopping há pouco tempo, a notícia veiculada no jornal e no outdoor sobre a entrada de uma faculdade, inicialmente não corroborada por nenhuma outra fonte, surpreendeu os entrevistados e foi percebida como duvidosa. Com o intuito de verificar a veracidade do fato, na primeira fase - compreensão inicial da situação - os entrevistados recorreram a várias fontes de informação. Inicialmente, procuraram a diretoria do shopping, que não confirmou a notícia. Passados alguns meses, uma noiva procurou o buffet para cancelar sua festa de casamento, com a informação de que a faculdade realmente passaria a funcionar no shopping. Os entrevistados novamente procuraram a diretoria do shopping, que continuou negando essa informação. Por causa da incerteza, a empresa recorreu a outras fontes para verificar se a situação era possível, como atas e regulamentos de condomínio.

Evidencia-se que, desde a notícia do jornal até a confirmação da situação problemática, os entrevistados experienciaram emoções de surpresa, frustração e expectativa, como exemplificado pelo relato abaixo:

"Acho que a gente ficou sentida, chateada de ter sido passada para trás. Não é a maneira como a gente costuma agir com as pessoas. Então o que a gente espera, o que a gente esperava é que fosse da mesma maneira, mas com a gente não foi. Então a gente foi passada para trás, o sentimento é esse".

As emoções implicadas nos relatos narrados, de acordo com a teoria da cognição situada, são reconhecidas como 
constituintes das ações cognitivas dos sujeitos, enquanto disposições para a ação. Mas como observar essas emoções? Primeiro, atentando-se não só para as descrições objetivas de tais emoções pelos entrevistados em seus discursos, mas também observando a conduta de cada entrevistado durante os encontros, ouvindo repetidamente as gravações das entrevistas, lendo suas transcrições e acompanhando as anotações feitas durante cada entrevista (como registros de posturas corporais, gestos, entonação e tons de voz).

Nessa fase de compreensão inicial da situação, as emoções experienciadas estavam associadas às buscas recorrentes, intensivas e desgastantes, em sua maioria dirigidas à mesma fonte de informação. A recorrência à mesma fonte estava relacionada a uma história de relações previamente estabelecida e à congruência entre os domínios em que tanto os entrevistados quanto os administradores do shopping transitavam (note-se que somente as informações provenientes dessa fonte foram determinadas como perturbações legítimas pelos membros da empresa, apesar das evidências contrárias), o que sugere que a confiabilidade esteja relacionada aos usos anteriores bem-sucedidos da fonte em outras experiências.

Diante do problema apresentado, na próxima fase configuração da situação - os entrevistados procuraram confrontar as informações disponíveis sobre a situação com a história de relação estabelecida entre a empresa e o shopping, entre a empresa e os clientes, e com os princípios, crenças e valores familiares, a fim de compreender a situação que estava sendo configurada e justificar as ações tomadas. Nos relatos, observou-se que essas descrições das relações e os valores familiares apareceram recorrentemente perto das definições do problema, o que sugere que esses aspectos tenham sido utilizados para possibilitar uma construção de um conjunto de significados ou interpretações que permitissem reduzir a equivocidade das informações provenientes do ambiente de negócios da empresa, e uma interpretação plausível que pudesse ser utilizada para dar sentido ao que estava acontecendo.

Freqüentemente os gerentes vivenciam situações com questões mal definidas, que conduzem a múltiplas interpretações na maioria das vezes conflitantes. Nessas situações, a própria definição do problema é complexa e as pessoas envolvidas na situação são forçadas a encontrar um consenso a respeito do problema e a buscar soluções para o mesmo (DAFT; LENGEL, 1986). O conceito proposto por Weick (1973) para representar essa multiplicidade de sinais vagos, ambíguos e conflitantes do ambiente externo que conduz a diferentes interpretações e impossibilita uma definição clara e precisa das dimensões do problema experienciado pela organização é o de equivocidade (equivocality). Quando a equivocidade é alta, como na situação descrita, os membros da organização não sabem o que especificamente perguntar, ou, dito de outra forma, a informação que se procura não visa a responder a uma questão determinada, mas a chegar a um consenso sobre o que está ocorrendo.

Recorrendo aos princípios da cognição situada para explicar como se dão essas percepções e interpretações do ambiente, observa-se que a adequação comportamental que os sujeitos exibem ao longo de suas vidas é fruto da própria história de interações que esses sujeitos mantêm no meio, em um fluir de mudanças estruturais sempre congruentes. Daí a importância da história de vida dos entrevistados, das relações estabelecidas e mantidas com os clientes e com os administradores do shopping na determinação daquilo que se supõe ser o mais adequado e satisfatório a cada instante, como resultado de uma história em que adequações e congruências ao meio foram pré-experimentadas em outras situações. Isso pôde ser observado na medida em que, diante de uma situação equívoca, os entrevistados procuraram orientar-se de uma maneira que lhes parecia mais plausível e, certamente, mais condizente com seus domínios experienciais, seus princípios, crenças, valores e relações.

Assim, nessa fase de configuração da situação, destacaramse a preocupação com os clientes e a atenção dada a eles, a importância dos anos de convivência com os administradores do shopping e a indignação diante de suas condutas, como observado na fala abaixo:

"Uma vez que a gente renovou um contrato, se vocêé o dono do imóvel, se você está com a intenção de mudar o seu imóvel para um outro tipo de coisa, acho que o correto da sua parte é avisar: 'Olha, eu estou com a intenção de fazer isso, você vai querer mesmo assim renovar o seu contrato, você está renovando agora, você é um cliente de tantos anos, sempre foi correto, sempre pagou as coisas direito, então eu acho que te devo uma satisfação da minha idéia'. E da parte deles [referindo-se aos administradores do shopping], não teve isso, entendeu? Então eu acho que foi desonesto da parte deles".

Destacou-se também a convergência de visão que ressalta os valores adquiridos nos domínios familiares, como ilustrado no discurso de dois dos entrevistados:

"São pessoas que só pensam em dinheiro [referindo-se aos administradores do shopping], que não têm os princípios morais que você tem desde a infância."

"Eu gosto das coisas muito certas, muito corretas, acho que as pessoas têm que ser leais, você tem que poder confiar nas pessoas, na palavra delas. Então eu acho que o pessoal do shopping fugiu muito de todas as regras que para nós são valores importantes." 
É interessante observar que apenas um dos diretores, o único não pertencente ao grupo familiar, não fez menção explícita a esses valores quando do seu relato da situação.

Definidas as dimensões do problema e configurada a situação, na terceira fase - definição de cursos de ação - faziam-se necessárias a identificação das repercussões dessa mudança e as possíveis soluções para o ocorrido. Nessa fase, destacou-se a busca ativa por informações nos diversos domínios de atuação dos entrevistados (informações jurídicas, contatos com amigos, funcionários, consultores e clientes). Essas informações se reforçaram e auxiliaram na interpretação da situação, no esclarecimento de preferências e na definição de possíveis cursos de ação. Assim, adquiriu relevo o uso concomitante de vários tipos de fontes de informação, preponderando a busca em fontes externas. Ressaltou-se, ainda, a utilização das relações pessoais como fontes de informação, como exemplificado no relato abaixo:

"Quando aconteceu toda a situação nós vimos que não
podíamos ficar porque foram indo noivas no buffet, pessoas
foram cancelando eventos. Aí, o que eu fiz? Eu fui a campo.
Eu falo que ir a campo é questionar pessoas que são formadoras
de opinião e são pessoas de certa forma eticamente, (...) são
altos executivos ou empresários e que podem contribuir pela
experiência que eles têm. A minha mãe foi questionando
pessoas da relação dela e o meu irmão também e nós fomos
amadurecendo (...). A gente ouviu muitas pessoas, ouviu
opiniões diferentes, até chegar a um consenso. Depois nós
pegamos as minhas gerentes e falamos: 'Gente, o que vocês
acham?' São os prós e os contras de funcionar em um lugar
onde vai ter uma outra empresa e uma empresa que é uma
faculdade. Aí, todo mundo foi analisando. [Também] Ligamos
para alguns clientes. Nós procuramos estar sempre ouvindo o
cliente externo e interno."

Dois aspectos interessantes de serem analisados nessa fase referem-se à relevância e à acessibilidade das fontes de informação. A relevância das fontes, nesse caso específico, está relacionada à importância dos contatos pessoais. Há uma história prévia de relações com os membros da organização, os contatos conhecem os processos da empresa e os domínios nos quais os administradores e a empresa transitam. As fontes pessoais são parte das histórias de vida e das relações dos entrevistados, e há um envolvimento emocional que facilita a percepção da objetividade e a sinceridade de uma informação considerada adequada - dado o conhecimento do domínio.

Outra questão é a da acessibilidade. Culnan (1985) considerou a acessibilidade bidimensionalmente. A primeira dimensão relaciona-se ao estabelecimento do contato com a fonte. A segunda, com o processo de obtenção de informações da fonte. O contato inicial com a fonte está relacionado com a história de relações pessoais, profissionais, e das diversas interações estabelecidas. Essas fontes pessoais usualmente conhecem melhor os domínios em que os entrevistados transitam e podem fornecer informações mais relevantes. Importante também é o processo de obtenção de informações dessas fontes, fortemente determinado pela familiaridade com o domínio e pelas emoções experienciadas. As fontes só fornecem certos tipos de informação para determinadas pessoas, ou seja, tem de existir confiança, uma pré-disposição favorável e a esperança de que a informação seja bem compreendida (o que depende da congruência dos domínios). Ao mesmo tempo, os entrevistados só determinaram as perturbações informacionais em seus domínios porque essas perturbações foram desencadeadas por determinadas fontes em determinados domínios (isso institui, em parte, o julgamento da relevância da informação). O relato de uma das entrevistadas exemplifica essa discussão. Talvez em um outro domínio, ou vinda de outra fonte de informação, a expressão "paisagem" pudesse ser entendida como uma crítica ou insulto, mas aqui ela é compreendida como uma motivação para a mudança:

Um outro amigo meu desse grupo do YPO [grupo de executivos denominado Young Presidents' Organization do qual a entrevistada participa] falou: 'A gente às vezes demora a tomar uma decisão porque a gente se acomoda em certas situações que a gente vive. Você está lá no [cita o nome do shopping], aluga super bem, já está lá há 12 anos, só que você às vezes esqueceu que você virou paisagem ali. Então, de vez em quando, a gente tem que mudar um pouco a paisagem. Você virou uma paisagem, está há 12 anos na mesma coisa. Doze anos já é hora de mudar!' ".

Evidencia-se que a fase de definição de cursos de ação a serem seguidos não é conclusiva, dada a natureza estratégica e nãolinear da decisão em análise. Assim percebeu-se uma nova fase - reconfiguração da situação. Nesse estágio, no entanto, não se tratava de definir novas ações, mas de construir novos entendimentos para a situação tendo em vista as soluções consideradas na fase anterior, o que, por sua vez, possibilitou o estabelecimento de novas alternativas de ação. A reconfiguração da situação se deu de maneira diferente para cada entrevistado e, por vezes, conflitante. Para alguns, a reconfiguração foi expressa pelo desejo de solucionar o problema mediante a rescisão do contrato, após a realização das festas e dos eventos contratados, e da mudança para um outro espaço. Para outros, a situação vivenciada foi vista como possibilitadora de crescimento e aprendizado pessoal e profissional. Ainda, a situação foi entendida como uma oportunidade, e a melhor solução seria a modificação do segmento das festas do salão.

Como nas fases anteriores, as histórias de relação com o shopping e com os clientes foram utilizadas para justificar as ações tomadas, e o contato pessoal foi determinante para uma nova compreensão da situação e para redefinição dos possíveis cursos de ação, como ilustrado pela fala a seguir: 
"Há mais tempo eu tenho uma pessoa que tem me procurado para montar um salão infantil. Ele mexe muito com criança e ele é dono dessas academias infantis para criança. Então há um ano e meio nós estamos evoluindo na história de criar um salão infantil que tenha uma situação de brinquedo ou de atividades completamente diferente do que você vê atualmente (...). [Além disso] as pessoas ligam muito perguntando se a gente tem um salão infantil, e os parceiros que temos demonstram claramente que não tem data suficiente para atender a toda a demanda."

Na fase inicial, preponderaram as emoções de frustração e decepção experienciadas pelos entrevistados ao buscarem informações para a construção do problema e a compreensão da situação. Na fase atual, vemos a mudança dessas emoções. Quando a situação parecia mais clara e definida, com a identificação de possíveis soluções para o problema, os entrevistados experienciaram emoções de otimismo, confiança, entusiasmo e esperança, buscando informações em fontes diversificadas e determinando-as de modo mais construtivo, como mostra o seguinte exemplo:

"Nós estamos olhando um outro salão e tomamos a decisão de que vamos fazer um negócio com uma determinada pessoa que está nos propondo e que a gente acha que vai ser um sucesso! (...) Vamos ter realmente um salão. Vai ser uma coisa muito boa, vai ser muito bem posicionado, vai ter estacionamento e não vai estar dentro de nenhum prédio que a gente corra risco de no final ter uma mudança e atrapalhe, como teve agora no [cita o nome do shopping]."

Então, a reconfiguração da situação refletiu uma mudança nas emoções, entrada em novos domínios com informações novas, estabelecimento ou intensificação de novas relações e, ao mesmo tempo, uma continuação das histórias e ponto de partida de novas histórias. Mais do que uma tomada de decisão efetiva, o que se observou foi uma modificação de compreensão da situação de modo a viabilizar novas alternativas para futuras decisões.

Nitidamente, durante o processo decisório, foram privilegiados pelos entrevistados aspectos como a emoção, as experiências vivenciadas, a história de vida e as histórias de relações com outras pessoas, em detrimento dos aspectos mais racionais, lineares e processuais.

Corroborando as análises realizadas por Dervin $(1983,1992)$ e Kuhlthau (1991, 1993a), a informação foi para a configuração do problema e suas possíveis soluções. Em relação a Dervin, perceberam-se diversos momentos de busca de informação para a construção de sentido, não para resolver o problema em si, mas para a compreensão do problema vivenciado.

Como discutido por Kuhlthau e observado no estudo, nas fases iniciais da busca, os entrevistados experienciaram emoções de incerteza e frustração que deram lugar a emoções de confiança e entusiasmo quando a situação parecia mais clara e quando surgiram prováveis soluções para o problema. Embora não se tenha a pretensão de determinar fases genéricas para o comportamento de busca de informação, algumas delas são freqüentes, como as emoções vivenciadas aqui retratadas e suas alternâncias.

Observa-se, ainda, certa congruência de conduta dos entrevistados nas fases de compreensão inicial da situação e definição de cursos de ação a serem seguidos (primeira e terceira fases) e nas fases de configuração e reconfiguração da situação (segunda e quarta). Assim, nota-se que as fases nas quais preponderaram as buscas de informação (primeira e terceira) foram entremeadas por fases de uso da informação (segunda e quarta), ou, dito de outra forma, observa-se que mudanças no domínio da organização desencadearam fases de busca de informação que, por sua vez, possibilitaram a compreensão e a reconfiguração da situação (uso da informação).

Assim, na primeira fase, notou-se a busca ativa e intensa por informações, concentrada em determinadas fontes e motivada pela necessidade de confirmar as informações obtidas pela exposição passiva. Na terceira fase, na qual a busca por informações foi mais intensa, ativa e mais abrangente que em qualquer outra fase, percebeu-se a recorrência a múltiplas fontes de informação. Nessa fase, a busca teve um caráter mais preponderante de descoberta do que de esclarecimentos de situações. Já na segunda e quarta fases, a busca objetivou a interpretação da situação de informação, ou seja, ocorreu uma reciclagem dos valores, das crenças e das emoções, de forma a harmonizar entendimentos e estabelecer compreensões comuns. 
Sumarização dos resultados da pesquisa

\begin{tabular}{|c|c|c|c|c|c|c|}
\hline $\begin{array}{l}\text { Fases da } \\
\text { situação }\end{array}$ & Descrição da fase & Uso da informação & $\begin{array}{l}\text { Principais fontes de } \\
\text { informação utilizadas }\end{array}$ & $\begin{array}{l}\text { Percepções das fontes de } \\
\text { informação }\end{array}$ & $\begin{array}{l}\text { Emoções } \\
\text { envolvidas }\end{array}$ & $\begin{array}{c}\text { História de relações e } \\
\text { interações }\end{array}$ \\
\hline $\begin{array}{l}\text { Configuração } \\
\text { da situação }\end{array}$ & $\begin{array}{l}\text { Esforços para } \\
\text { compreender } 0 \\
\text { ocorrido e para } \\
\text { determinar a } \\
\text { amplitude de suas } \\
\text { repercussões }\end{array}$ & $\begin{array}{l}\text { Construção de } \\
\text { significados } \\
\text { para reduzir a } \\
\text { equivocidade do } \\
\text { ambiente externo e } \\
\text { uma interpretação } \\
\text { plausível para dar } \\
\text { sentido ao que estava } \\
\text { acontecendo }\end{array}$ & $\begin{array}{l}\text { Demais membros da } \\
\text { família (pessoal interna) } \\
\text { Administradores do } \\
\text { shopping, clientes } \\
\text { (pessoal externa). }\end{array}$ & $\begin{array}{l}\text { Acesso a fontes pessoais } \\
\text { consideradas confiáveis ou } \\
\text { diretamente relacionadas à } \\
\text { situação vivenciada }\end{array}$ & $\begin{array}{l}\text { Indignação } \\
\text { Decepção } \\
\text { Raiva }\end{array}$ & $\begin{array}{l}\text { Recorrência aos } \\
\text { princípios, crenças e } \\
\text { valores familiares, e } \\
\text { relações estabelecidas } \\
\text { com os clientes e } \\
\text { administradores } \\
\text { do shopping para } \\
\text { compreensão da } \\
\text { situação vivenciada. }\end{array}$ \\
\hline $\begin{array}{l}\text { Definição de } \\
\text { cursos de } \\
\text { ação a serem } \\
\text { seguidos }\end{array}$ & $\begin{array}{l}\text { Busca de informação } \\
\text { para reformulação } \\
\text { da situação e para } \\
\text { determinação de } \\
\text { possíveis soluções }\end{array}$ & $\begin{array}{l}\text { Identificação das } \\
\text { repercussões da } \\
\text { mudança e possíveis } \\
\text { soluções para } 0 \\
\text { ocorrido }\end{array}$ & $\begin{array}{l}\text { Informações jurídicas, } \\
\text { atas de condomínio, } \\
\text { legislação municipal } \\
\text { (impessoal externa). } \\
\text { Funcionários da empresa } \\
\text { (pessoal interna) }\end{array}$ & $\begin{array}{l}\text { Fontes pessoais percebidas } \\
\text { como confiáveis e relevantes. } \\
\text { Fontes impessoais provendo } \\
\text { dados considerados } \\
\text { adequados à situação mais } \\
\text { bem definida. }\end{array}$ & $\begin{array}{l}\text { Otimismo } \\
\text { Confiança }\end{array}$ & $\begin{array}{l}\text { Relações pessoais } \\
\text { e profissionais } \\
\text { determinantes } \\
\text { da relevância da } \\
\text { informação }\end{array}$ \\
\hline $\begin{array}{l}\text { Reconfiguração } \\
\text { da situação }\end{array}$ & $\begin{array}{l}\text { Compreensão atual da } \\
\text { situação contrastada } \\
\text { com a inicial e as } \\
\text { diferentes maneiras } \\
\text { como as pessoas } \\
\text { compreendem e } \\
\text { navegam na situação }\end{array}$ & $\begin{array}{l}\text { Construção de novas } \\
\text { configurações que } \\
\text { possibilitassem a } \\
\text { aceitação das ações } \\
\text { consideradas na } \\
\text { fase anterior e } 0 \\
\text { estabelecimento de } \\
\text { novas alternativas }\end{array}$ & $\begin{array}{l}\text { Amigos, consultores } \\
\text { (pessoal externa). } \\
\text { Fontes diversificadas }\end{array}$ & $\begin{array}{l}\text { As diversas fontes foram } \\
\text { avaliadas positivamente } \\
\text { à medida que proviam } \\
\text { informações congruentes } \\
\text { com as expectativas de cada } \\
\text { um dos envolvidos }\end{array}$ & $\begin{array}{l}\text { Entusiasmo } \\
\text { Esperança }\end{array}$ & $\begin{array}{l}\text { Relações pessoais } \\
\text { importantes para uma } \\
\text { nova compreensão } \\
\text { da situação e para } \\
\text { definição de possíveis } \\
\text { cursos de ação. }\end{array}$ \\
\hline
\end{tabular}

\section{CONSIDERAÇÕES FINAIS}

Uma grande parte dos estudos existentes que analisam o comportamento informacional considera a busca de informação como um processo construído em estágios ou fases, por vezes interativas. O que se encontra subjacente a esses estudos é a idéia de que a busca de informação é sempre desencadeada pela identificação de um gap informacional, ou, dito de outra forma, pelo reconhecimento de um estado cognitivo insuficiente ou inadequado para resolução de um problema ou tópico específico. Subjacente, ainda, está a idéia de que a informação é um fator possibilitador de mudanças das estruturas cognitivas, a qual, percebida, transforma o estado de conhecimento do indivíduo. Essas abordagens são menos holísticas e integrativas de aspectos como as interações sociais, as emoções e a linguagem.

No entanto, modelos mais abrangentes têm procurado valorizar o contexto em que se realiza a busca de informação e agregar, em suas análises, aspectos cognitivos e emocionais experienciados durante esse processo (como os modelos propostos por Kuhlthau e Dervin). Embora essas abordagens apresentem certa evolução quando comparadas aos demais modelos tradicionais, elas continuam enfatizando os aspectos cognitivos individuais, atentando menos para as dimensões coletivas da busca de informação. Essas limitações devemse, em parte, à teoria cognitiva, à qual esses modelos estão atrelados.

Diante desse contexto, acredita-se que as pesquisas de busca de informação necessitem de novas perspectivas para formular seus problemas e metodologias. Assim é que, ao longo deste artigo, procurou-se mostrar que a cognição situada pode ser utilizada para a explicação dessas questões informacionais. A proposta da pesquisa foi baseada na natureza situacional da busca de informação, possibilitando uma nova compreensão do comportamento informacional ao incorporar os aspectos cognitivos, emocionais e relacionais nas explicações. 
A cognição situada revelou-se como uma abordagem extremamente adequada e de grande valia para a análise do comportamento de busca de informação, uma vez que permitiu entender que aquilo que se distingue e se especifica cognitivamente nos diversos domínios nos quais se atua, a compreensão e as interpretações construídas com os outros e as decisões tomadas dependem das interações mantidas ao longo da história particular de vida de cada sujeito, das possibilidades no instante da sua dinâmica estrutural, das suas disposições corporais para a ação e das suas experiências como ser histórico e contingente que vive com outros sujeitos na linguagem.

Assim, a cognição situada possibilitou a consideração não somente dos aspectos que são usualmente analisados pelas teorias cognitivas tradicionais no campo da ciência da informação, mas de outras questões igualmente importantes e, de certa forma, mais difíceis de serem abordadas, como a história e as condutas dos sujeitos no domínio de ação em que estão sendo observados, os contatos que estabelecem no cotidiano, como e por qual razão eles ocorrem e as disposições emocionais vivenciadas em situações específicas.

Artigo submetido em 26/08/2007 e aceito para publicação em 22/08/2008.

\section{REFERÊNCIAS}

BARDIN, L. Análise de conteúdo. Lisboa: Edições 70, 1988.

BATESON, G. Steps to an ecology of mind. New York: Ballantine, 1972.

BORGES, M. E. N. A informação e o conhecimento na biologia do conhecer uma abordagem cognitiva para os estudos sobre inteligência empresarial. 2002. 165 f. Tese (Doutorado Ciência da Informação)Escola de Ciência da Informação, Universidade Federal de Minas Gerais, Belo Horizonte, 2002.

CHÉR, R. A gerência das PME: o que saber para administrá-las. São Paulo: Maltese, 1990.

CLANCEY, W. J. Situated cognition: on human knowledge and computer representations. Cambridge University Press, 1997.

CULNAN, M. J. The Dimensions of perceived accessibility to information: implications for the delivery of information systems and services. Journal of the American Society for Information Science, v. 36, n. 5, p. 302-308, 1985.

DAFT, R.L.; LENGEL, R. H. Organizational information requirements, media richness and structural design. Management Science, v. 32, n. 5, p. 554-571, 1986.

DERVIN, B. An overview of sense-making research: concepts, methods and results to date. In: INTERNATIONAL COMMUNICATION ASSOCIATION ANNUAL MEETING, 1983, Dallas. Proceedings... Dallas, 1983.

From de mind's eye of the 'user': the sensemaking qualitative-quantitative methodology. In: GLAZIER, J. D.; POWELL, R. R. (Ed.). Qualitative research in information management. Englewood: Libraries Unlimited, 1992.

. Verbing communication: mandate for disciplinary invention. Journal of Communication, v. 43, n. 3, p. 45-54, 1993.

FLANAGAN, J. C. The critical incident technique. Psycological Bulletin, v. 51, n. 4, p. 327-358, 1954.
KUHLTHAU, C. C. Inside the search process: information seeking from the user's perspective. Journal of the American Society for Information Science, v. 42, n. 5, p. 361-371, 1991.

. A principle of uncertainty for information seeking. Journal of Documentation, v. 49, n. 4, p. 339-355, 1993 b.

. Seeking meaning: a process approach to library and information services. Norwood, NJ: Ablex, 1993 .

MATURANA, H. R. A ontologia da realidade. Belo Horizonte: Editora UFMG, 1997.

- Cognição, ciência e vida cotidiana. Tradução e organização Cristina Magro e Victor Paredes. Belo Horizonte: UFMG, 2001.

. Emoções e linguagem na educação e na política. Tradução José Fernando Campos Fortes. Belo Horizonte: UFMG, 1998.

; VARELA, F. J. A árvore do conhecimento: as bases biológicas da compreensão humana. Tradução Humberto Mariotti; Lia Diskin. 4. ed. São Paulo: Palas Athenas, 2004.

SAVOLAINEN, R.; TUOMINEN, K.; TALJA, S. The social constructionist viewpoint to information practices. In: FISHER, K. E.; ERDELEZ, S.; MCKECHNIE, L. Theories of information behaviour. Medford, NJ: Information Today, 2005. p. 328-333.

STRAUSS, A. L. Qualitative analysis for social scientists. Cambridge: [s. n.], 1987.

TALJA, S.; KESO, H.; PIETILÄINEN, T. The production of context in information seeking research: a metatheoretical view. Information Processing and Management, v. 35, p. 751-763, 1999.

VARELA, F.; THOMPSON, E.; ROSCH, E. The embodied mind: cognitive science and human experience. Cambridge: MIT Press, 1991.

WEICK, K. E. A psicologia social da organização. Tradução Dante Moreira Leite. São Paulo: Edgar Blücher, 1973. 